\section{(6) OPEN ACCESS}

\title{
Mortality and cancer incidence in ammonium perfluorooctanoate production workers
}

\author{
Katherine K Raleigh, ${ }^{1}$ Bruce H Alexander, ${ }^{1}$ Geary W Olsen, ${ }^{2}$ \\ Gurumurthy Ramachandran, ${ }^{1}$ Sandy Z Morey, ${ }^{3}$ Timothy R Church, ${ }^{1}$ Perry W Logan, ${ }^{2}$ \\ Laura L F Scott, ${ }^{1}$ Elizabeth M Allen ${ }^{1}$
}

\begin{abstract}
${ }^{1}$ Division of Environmental Health Sciences, School of Public Health, University of Minnesota, Minneapolis, Minnesota, USA

23M Company, Saint Paul, Minnesota, USA

${ }^{3}$ More Consulting, Inc., Saint Paul, Minnesota, USA
\end{abstract}

\section{Correspondence to} Dr Bruce H Alexander, Division of Environmental health Sciences, School of Public Health, University of Minnesota, MMC 807 Mayo Building, 420 Delaware Street S.E., Minneapolis, MN 55455, USA: balex@umn.edu

Received 20 January 2014 Revised 3 April 2014 Accepted 27 April 2014 Published Online First 15 May 2014

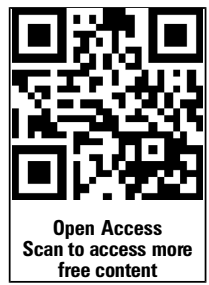

CrossMark

To cite: Raleigh $\mathrm{KK}$ Alexander BH, Olsen GW, et al. Occup Environ Med 2014;71:500-506.

\section{ABSTRACT}

Objective To evaluate mortality and cancer incidence in a cohort of ammonium perfluorooctanoate (APFO) exposed workers.

Methods We linked a combined cohort $(n=9027)$ of employees from APFO and non-APFO production facilities in Minnesota to the National Death Index and to cancer registries of Minnesota and Wisconsin. Industrial hygiene data and expert evaluation were used to create a task-based job exposure matrix to estimate APFO exposure. Standardised mortality ratios were estimated using Minnesota population rates. HRs and 95\% Cls for time-dependent cumulative APFO exposure were estimated with an extended Cox model. A priori outcomes of interest included cancers of the liver, pancreas, testes, kidney, prostate and breast, and mortality from cardiovascular, cerebrovascular and chronic renal diseases.

Results Mortality rates in the APFO-exposed cohort were at or below the expected, compared with Minnesota. The HR for dying from the cancer and noncancer outcomes of interest did not show an association with APFO exposure. Similarly, there was little evidence that the incident cancers were associated with APFO exposure. Compared to the non-exposed population, modestly elevated, but quite imprecise HRs were observed in the higher-exposure quartiles for bladder cancer $(\mathrm{HR}=1.66,95 \% \mathrm{Cl} 0.86$ to 3.18) and pancreatic cancer $(\mathrm{HR}=1.36,95 \% \mathrm{Cl} 0.59$ to 3.11). No association was observed between APFO exposure and kidney, prostate or breast cancers.

Conclusions This analysis did not support an association between occupational APFO exposure and the evaluated health endpoints, however, the study had limited power to evaluate some conditions of interest.

\section{BACKGROUND}

Ammonium perfluorooctanoate (APFO, CAS No. $\left.3825-26-1, \mathrm{C}_{7} \mathrm{~F}_{15} \mathrm{COO}^{-} \mathrm{NH}_{4}\right)$ is the ammonium salt of perfluorooctanoic acid (CAS No. 335-67-1, PFOA, $\left.\mathrm{C}_{7} \mathrm{~F}_{15} \mathrm{COOH}\right)$, and has been used as a surface-active agent in the polymerisation process for many fluoropolymers. APFO and PFOA are not metabolised, but rapidly dissociate in blood to the perfluorooctanoate anion $\left(\mathrm{C}_{7} \mathrm{~F}_{15} \mathrm{COO}^{-}\right)$where it readily binds to serum proteins. Two chronic feeding studies of APFO in rats have reported increased incidence of hepatocellular adenomas, ${ }^{1}$ pancreatic cell adenomas ${ }^{1}$ and hyperplasia, ${ }^{2}{ }^{3}$ and Leydig cell adenomas of the testes. ${ }^{12}$ PFOA is an

\section{What this paper adds?}

- The human health effects of ammonium perfluorooctanoate (APFO) and perfluorooctanoic acid (PFOA) continue to be investigated. Studies of occupationally exposed population have reported associations between APFO and PFOA exposure and certain diseases, including prostate and kidney cancers, and diabetes and chronic renal disease.

- In this analysis, we update a mortality study of an APFO production cohort with an improved exposure reconstruction, add a non-APFO-exposed referent population from the same company, and include a linkage to cancer registries to evaluate incident cancers.

- This study does not support previously reported associations in this cohort between APFO exposure and risk of prostate and kidney cancer and diabetes, and stroke, or associations with kidney cancer and chronic renal disease in another occupational cohort. This analysis does not support an association between APFO and liver and pancreatic cancers in humans. The study, however, had limited power to evaluate exposure response for some outcomes, particularly testicular, thyroid, bladder, liver and pancreatic cancers.

agonist for several xenosensor nuclear receptors (PPAR $\alpha, \mathrm{CAR} / \mathrm{PXR})$ that result in an early hepatocellular proliferative response, but this mode of action is unlikely to pose a risk in humans. ${ }^{4}$

Occupational exposures in the manufacture of APFO and its use as a surface-acting agent in fluoropolymer production have resulted in serum PFOA measured in workers at low $\mu \mathrm{g} / \mathrm{mL}$ levels. ${ }^{6} 7$ PFOA has also been measured in the serum of the general population at low $\mathrm{ng} / \mathrm{mL}$ concentrations. ${ }^{8}{ }^{9}$ General population exposures include direct (eg, food and water) and indirect (eg, biotransformation of fluorotelomer alcohols) sources. ${ }^{10}$ Contamination of drinking water sources has resulted in higher average serum PFOA concentrations of the affected communities than the general population, but below occupational levels. ${ }^{6} 711$ Concerns over the widespread environmental presence of PFOA and another perfluorooctanyl compound, perfluorooctanesulfonate 
(PFOS), led to the phase-out by a major manufacturer, $3 \mathrm{M}$ Company, in 2000-2002. A 2006 PFOA stewardship programme of the US EPA and eight manufacturers is targeting the complete phase-out of PFOA by 2015.

Studies in occupationally exposed populations have yielded some evidence, albeit inconsistent, of potential health effects in humans. A cohort mortality study of the DuPont Washington Works (Parkersburg, West Virginia, USA) polytetrafluoroethylene (PTFE) plant, where APFO was used as a processing aid, reported chronic renal disease and kidney cancer associated with increasing occupational exposure to PFOA. ${ }^{12}$ Tetrafluoroethylene (TFE) exposure was highly correlated with PFOA exposure, and TFE is a kidney carcinogen in rats. ${ }^{13}$ Consonni et $a l^{14}$ examined the effect of this joint exposure of PFOA and TFE in a multiplant cohort study of TFE synthesis and polymerisation workers that included a sizable subset of workers from the DuPont Washington Works plant. Estimated units of exposure to TFE and PFOA were developed but were highly correlated, thus, the independent causal association of PFOA and TFE with kidney cancer could not be identified. Analyses of employees at the $3 \mathrm{M}$ Company APFO production site in Cottage Grove, Minnesota, reported higher risks of death from prostate cancer and stroke among the highest exposed production workers compared to the lowest. ${ }^{15} 16$ These analyses were limited by the qualitative nature of the exposure assessment and that the lowest exposed members of the population were more likely to be research and development professionals with lower overall baseline risks.

Here we present an updated mortality analysis and a new cancer incidence analysis of the Cottage Grove cohort and a non-exposed referent population from a nearby $3 \mathrm{M}$ Company plant. The current study includes an extensive task-based job exposure data matrix (EDM) for APFO using industrial hygiene air monitoring data. Based on the epidemiological and toxicological literature as well as the previous findings reported at the Cottage Grove plant a priori outcomes of interest included cancers of the liver, pancreas, testes, kidney, prostate and breast, and mortality from cardiovascular, cerbrovascular and chronic renal diseases.

\section{METHODS}

The protocol for this study was reviewed and approved by the Human Subjects Committee of the University of Minnesota.

\section{Study population}

The study population included employees of two $3 \mathrm{M}$ facilities in the Minneapolis and Saint Paul metropolitan area who had accrued at least 365 days of employment. The 365-day restriction was implemented to ensure the study population represented the working population, and excluded short-term employment, such as students who may have interned for one or more summers. The APFO production facility was located in Cottage Grove, Minnesota. The Cottage Grove plant was constructed in 1947 and APFO production began soon thereafter. APFO production increased over time, but was phased out completely by the end of 2002. Eligible Cottage Grove employees $(n=4668)$ included 3993 from the previous study and 675 hired between 1997 and 2002. The Cottage Grove site had two divisions; chemical and non-chemical. The Chemical Division developed and produced APFO and other specialty chemicals (non-APFO). The Non-Chemical Division manufactured a variety of products (not involving APFO), including abrasives, films, glass bubbles, tape and automotive applications (traffic signs and mats for catalytic converters). The Chemical and
Non-Chemical Divisions housed research and development and pilot production activities, thus, the cohort included many nonproduction workers.

For a completely non-APFO-exposed production worker referent population we used a second $3 \mathrm{M}$ Company cohort that had been previously enumerated by the University of Minnesota. This referent cohort included 4359 employees of a tape and abrasives production facility in Saint Paul, Minnesota, who worked for at least 365 days before 1999. This population was similar to the APFO production workers as production workers employed by the company, and also located in the same geographic region and were represented by the same labour union. The total population of both locations included 9027 workers. A small group of 200 workers had employment records in both locations. These workers were included in the Cottage Grove population for the purpose of this analysis of APFO exposure.

\section{Determination of vital status and causes of death}

We completed a vital status assessment on all cohort members not identified as deceased in the previous follow-up. ${ }^{16}$ The cohort was submitted to the Social Security Administration's (SSA) service for epidemiologic studies to identify the deceased and confirm status of living cohort members. A commercial skip-tracing vendor was used to further explore the vital status of workers who were not clearly identified as alive or deceased through the SSA. We submitted all cohort members not determined to be alive to the National Death Index (NDI). The date of death, state of death, and underlying and contributing cause of death were obtained for all matches. Ultimately, the vital records search confirmed vital status for all but $61(0.67 \%)$ members of the cohort. The causes of death were coded to the International Classification of Disease (ICD) version in effect at the time of death. The complete mortality records were available through 2008 .

\section{Cancer incidence}

The company facilities were located in east central Minnesota close to the Wisconsin border, and some members of the cohort resided in Wisconsin. We identified incident cancers of interest through a linkage to the Minnesota Cancer Surveillance System (MCSS) and the Wisconsin Cancer Reporting System (WCRS). Both registries operate under state statute requiring mandatory reporting of cancer diagnoses for state residents. The MCSS was established in 1988. WCRS was established in 1976 as a passive system and became mandatory in the late 1980s. A protocol was developed to permit linkage of the occupational cohort to the cancer registry to identify selected cancers and return deidentified data for analysis. All cohort members alive as of 1 January 1988 were eligible for the cancer incidence follow-up. Cancer incidence, including date of diagnosis, cancer site and histology, was obtained for a selected set of cancers; liver, pancreas, testes, prostate, kidney, bladder, breast and thyroid. A potential source of bias in cancer cases ascertainment was out-migration from Minnesota and Wisconsin. In lieu of a comprehensive mechanism to evaluate out-migration for the entire cohort, we evaluated the state of death from the mortality records for decedents alive in 1988. The proportion of deaths occurring in Minnesota and Wisconsin was used as a surrogate measure of the case capture of the cohort.

\section{Exposure assessment and exposure models}

Production of APFO was a multistep process. PFOA was produced by electrochemical fluorination and then isolated and 
converted first to an APFO salt slurry, and then to a salt cake. The cake was dried and/or dissolved in water, packaged, and shipped to external customers. The production process offered several opportunities for worker exposure. Inhalation exposure occurred from the acid vapour and ammonium salt particulate phase during regular production duties and other responsibilities, such as cleaning the equipment, changing filters, quality control checks and maintenance. Additionally, low-level continuous exposure to APFO occurred from working in and around the general production environment without direct involvement in chemical production. We used work history records, industrial hygiene monitoring data, information from current and former workers and industrial hygiene professionals, and average annual APFO production levels to characterise occupational APFO exposure. Exposure estimates represented inhalation exposure for all cohort members expressed as a daily time-weighted average (TWA) in milligrams per cubic metre of air $\left(\mathrm{mg} / \mathrm{m}^{3}\right)$. Work history records, which included the job department, job title and start and end dates, were used to identify the duration and calendar period of employment.

The industrial hygiene data characterising APFO exposure was limited to APFO production areas in the Chemical Division (205 personal samples and 659 area samples). The data were from 1977 through 2000, but represented all processes and tasks related to production. The production processes prior to 1977 involved the same procedures and tasks, but the exposures were less due to lower production volume. A TWA was calculated for each combination of department, job title, work area, equipment, task and year to create an EDM that contained 23 departments and 45 job titles within the Chemical Division for all production years (1947-2002). The task-based exposure model incorporated the amount of time spent during an $8 \mathrm{~h}$ shift in up to three predefined work task areas; (1) exposure-associated tasks in the production area, (2) nonexposure tasks in the production area, and (3) tasks outside of the production area. TWAs for jobs in APFO production ranged from $1 \times 10^{-4}$ to $4.0 \times 10^{-1} \mathrm{mg} / \mathrm{m}^{3}$.

Job, department and time-specific TWAs were estimated for non-APFO production areas of the Chemical Division and the entire Non-chemical Division based on expert judgment that was informed by the relative proximity of the job to the production area and annual APFO production levels. The exposures for non-APFO production jobs in the Chemical Division ranged from $1 \times 10^{-8}$ to $3 \times 10^{-5} \mathrm{mg} / \mathrm{m}^{3}$. The exposure range within the Non-Chemical Division was considered to be between $1 \times 10^{-8}$ and $1 \times 10^{-6} \mathrm{mg} / \mathrm{m}^{3}$. Because of the widespread environmental presence of PFOA, all cohort members received some exposure from outside the workplace. The Saint Paul Plant workers were assigned a background level $\left(1 \times 10^{-9}-1 \times 10^{-7} \mathrm{mg} / \mathrm{m}^{3}\right)$ to reflect exposures in the general population equivalent to an exposure range one order of magnitude lower than the Non-Chemical Division workers.

The average annual production of APFO varied with fewer than 500 pounds produced in the early 1950s to around 360000 pounds in the 1990s. This variation was incorporated into the average annual TWA for production and nonproduction exposure estimates. We linked the department, job and year-specific TWAs to the employees' work history records. We calculated cumulative estimates of exposure based on the summation of daily TWAs by year.

\section{Data analyses}

The initial analysis compared the mortality experience of the cohort to that of the population of Minnesota. Complete referent data were available from 1960 onwards, thus, our mortality analysis was limited to deaths occurring between 1960 and 2008. Follow-up was from the date of eligibility to date of death or the end of 2008. We estimated age, sex, and calendar period standardised mortality ratios (SMR) for each location and by quartile of the cumulative APFO exposure distribution for the Cottage Grove cohort. Data on race were not available for the cohort. SMR and 95\% CIs were computed using the National Institute of Occupational Safety and Health's (NIOSH) software for Life Table Analysis System, ${ }^{17}$ which incorporates exposure as a time-dependent covariate.

To compare the APFO-exposed population with the nonexposed population, HR with $95 \%$ CIs for mortality and cancer incidence risk were estimated as a function of APFO timedependent exposure using extended Cox regression models. ${ }^{18}$ In these models, the Saint Paul workers were the referent population and APFO exposure in the Cottage Grove population was classified into quartiles. The time scale was age, beginning at the date of first employment for the mortality analysis and the later of date of first employment or 1 January 1988 (when registry data were available) for cancer incidence. Follow-up continued until death, diagnosis of the cancer of interest or end of follow-up. Models were adjusted for year of birth and sex. The analyses were conducted using the PHREG procedures in SAS V.9.2 (SAS Institute Incorporated, Cary, North Carolina, USA).

\section{RESULTS}

The cohort of 9027 experienced 2979 deaths. The cohort members from the two plants were similar in age of first employment, but the Saint Paul cohort was, on average, born 9 years earlier (table 1). Women represented only $12 \%$ of the Saint Paul cohort compared to $21 \%$ in Cottage Grove. Of the 2979 deaths, there were 72 prostate cancers, 48 pancreatic cancers, 16 bladder cancers, 25 female breast cancers, 24 kidney cancers and 15 liver cancers.

The SMRs for the Cottage Grove and Saint Paul cohorts revealed few differences in mortality rates with the state of Minnesota. Cottage Grove had lower SMRs for all causes $(\mathrm{SMR}=0.85,95 \% \mathrm{CI} 0.80$ to 0.90$)$, all cancers $(\mathrm{SMR}=0.87$, $95 \%$ CI 0.78 to 0.97 ), and ischaemic heart disease ( $\mathrm{SMR}=0.84$, 95\% CI 0.74 to 0.95 ) (table 2). The Saint Paul workers had higher rates of death from diabetes than the state of Minnesota population ( $\mathrm{SMR}=1.42$, 95\% CI 1.09 to 1.81 ) (table 2). Few

Table 1 Characteristics of cohort members from the Cottage Grove Plant (APFO exposure) and the Saint Paul Plant (referent)

\begin{tabular}{lccc}
\hline & $\begin{array}{l}\text { Cottage Grove } \\
\text { Plant }\end{array}$ & $\begin{array}{l}\text { Saint Paul } \\
\text { Plant }\end{array}$ & Total \\
\hline $\mathrm{n}(\%)$ & 4668 & 4359 & 9027 \\
& & & \\
Male (\%) & $3716(79)$ & $3834(88)$ & $7550(84)$ \\
Female (\%) & $952(21)$ & $526(12)$ & $1478(16)$ \\
Deaths (\%) & $1145(25)$ & $1834(42)$ & $2979(33)$ \\
Eligible for cancer & $4231(90.6)$ & $3787(86.9)$ & $8018(88.8)$ \\
follow-up (\%) & & & \\
& Mean (SD) & Mean (SD) & Mean (SD) \\
Year of birth & $1942(16.3)$ & $1933(14.6)$ & $1938(16.1)$ \\
Age at first employment & $29.3(8.9)$ & $28.6(8.3)$ & $29(8.6)$ \\
Age at follow-up & $63.2(14.1)$ & $68.8(11.5)$ & $65.9(13.2)$ \\
\hline APF0, ammonium perfluorooctanoate. & &
\end{tabular}


Table 2 Standardised mortality ratios (SMR) for selected causes of death for the Cottage Grove and Saint Paul cohorts

\begin{tabular}{|c|c|c|c|c|}
\hline \multirow{2}{*}{ Cause } & \multicolumn{2}{|c|}{ Cottage Grove Plant } & \multicolumn{2}{|c|}{ Saint Paul Plant } \\
\hline & Obs & SMR (95\% Cl) & Obs & SMR $(95 \% \mathrm{Cl})$ \\
\hline All causes & 1125 & $0.85(0.80$ to 0.90$)$ & 1829 & 0.98 (0.94 to 1.03$)$ \\
\hline All cancers & 332 & $0.87(0.78$ to 0.97$)$ & 514 & 1.04 (0.95 to 1.13$)$ \\
\hline Liver cancer & 8 & 0.81 (0.35 to 1.59$)$ & 7 & $0.55(0.22$ to 1.14$)$ \\
\hline Pancreatic cancer & 18 & 0.85 (0.50 to 1.34$)$ & 30 & 1.09 (0.74 to 1.56$)$ \\
\hline Prostate cancer & 24 & 0.83 (0.53 to 1.23$)$ & 48 & 1.03 (0.76 to 1.37$)$ \\
\hline Kidney cancer & 6 & $0.53(0.20$ to 1.16$)$ & 18 & 1.23 (0.73 to 1.95$)$ \\
\hline Breast cancer & 11 & $0.82(0.41$ to 1.47$)$ & 15 & 1.39 (0.78 to 2.29$)$ \\
\hline Bladder cancer & 8 & 0.89 (0.38 to 1.76$)$ & 8 & $0.62(0.27$ to 1.22$)$ \\
\hline Diabetes mellitus & 27 & $0.76(0.50$ to 1.11$)$ & 64 & 1.42 (1.09 to 1.81$)$ \\
\hline $\begin{array}{l}\text { Ischaemic heart } \\
\text { disease }\end{array}$ & 248 & 0.84 (0.74 to 0.95$)$ & 444 & 0.95 (0.87 to 1.05$)$ \\
\hline $\begin{array}{l}\text { Cerebrovascular } \\
\text { disease }\end{array}$ & 57 & 0.81 (0.61 to 1.05$)$ & 112 & $1.02(0.84$ to 1.23$)$ \\
\hline Chronic renal disease & 14 & 1.09 (0.60 to 1.84$)$ & 13 & 0.72 (0.38 to 1.24$)$ \\
\hline
\end{tabular}

SMRs by APFO exposure quartile were elevated for any of the outcomes, and those were not beyond chance (table 3 ).

To evaluate the risk of death in the APFO population compared to the Saint Paul workers, the exposure categories for kidney, bladder, liver and breast cancers were collapsed into high $(\mathrm{Q} 3 / 4)$ and low $(\mathrm{Q} 1 / 2)$ due to a small number of deaths from these causes. The workers with the higher APFO exposure (quartiles 3 or 4 ) had modestly elevated risk of death from prostate cancer (Q4: $\mathrm{HR}=1.32$, 95\% CI 0.61 to 2.84), bladder cancer (Q3-4: $\mathrm{HR}=1.96,95 \%$ CI 0.63 to 6.15 ), and chronic renal disease $(\mathrm{Q} 4: \mathrm{HR}=1.37,95 \% \mathrm{CI} 0.38$ to 4.95$)$, but the effects were not beyond chance. There was no evidence of elevated risk for kidney cancer. The cohort in the lowest quartile of APFO exposure had lower risks of death from prostate cancer $(\mathrm{HR}=0.34,95 \%$ CI 0.25 to 1.60$)$, cerebrovascular disease $(\mathrm{HR}=0.57,95 \%$ CI 0.32 to 1.02$)$, and diabetes $(\mathrm{HR}=0.27,95 \%$ CI 0.10 to 0.76$)$ (table 4$)$.

The incident cancer linkage identified the following cancers of interest (number of cases): prostate (441), kidney (35), pancreas (25), bladder (83), liver (9), breast (62), testes (5) and thyroid (5). No exposure response analysis was conducted for liver, testicular and thyroid cancers due to the small number of cases. Exposure categories were collapsed for the analysis of pancreatic cancer, and in supplemental analyses for breast and kidney cancer. For all cancers of interest there was little evidence that exposure to APFO increased the risk of cancer (table 5). The lowest-exposure quartiles in the Cottage Grove population had modestly lower risks for prostate cancer $(\mathrm{HR}=0.80,95 \% \mathrm{CI} 0.57$ to 1.11$)$, and the highest exposure was not substantially different than the referent population $(\mathrm{HR}=1.11,95 \%$ CI 0.82 to 1.49$)$. The analysis for kidney cancer was restricted to men as no women were diagnosed with kidney cancer. The risk of kidney cancer in the APFO exposed cohort did not differ appreciably with that of the non-APFO exposed population. The HRs for pancreatic cancer for the two highest quartiles combined $(\mathrm{HR}=1.36,95 \% \mathrm{CI} 0.59$ to 3.11$)$, and the two highest quartiles for bladder cancer were elevated, but the CIs were wide. The lowest exposed quartile had a lower risk of breast cancer compared with the Saint Paul facility $(\mathrm{HR}=0.36,95 \%$ CI 0.16 to 0.79$)$, and there was little evidence that higher exposure to APFO increased the risk of breast cancer. The results did not change appreciably when the exposures were lagged by 10 years (data not shown).

The analysis of potential impact of out-migration from the mortality records identified 2059 decedents alive in 1988. Overall, $85.8 \%$ had death certificates from Minnesota or Wisconsin. For exposure quartiles 1 through 4, the percentage was $68.8,77.4,88.6$, and $90.7 \%$, respectively, and $88.8 \%$ for the Saint Paul facility. This distribution lends support to our assertion that the higher exposed Cottage Grove workers are more similar to the Saint Paul workers than the lower exposed Cottage Grove workers. It also suggests a lower case ascertainment in the Cottage Grove employees who had less exposure.

\section{DISCUSSION}

In this analysis of APFO production facility workers, we did not observe an association between APFO exposure and the risk of several diseases of interest when compared to a nonAPFO-exposed population from the same company. Previous analyses of the Cottage Grove cohort reported an elevated risk of

Table 3 Standardised mortality ratios (SMR) by APFO exposure quartile in the Cottage Grove Population and the Saint Paul population

\begin{tabular}{|c|c|c|c|c|c|c|c|c|c|c|}
\hline \multirow[b]{3}{*}{ Cause } & \multicolumn{8}{|c|}{ Cottage Grove Plant exposure quartile* } & \multicolumn{2}{|c|}{ St Paul Plant } \\
\hline & \multicolumn{2}{|l|}{ Q1 } & \multicolumn{2}{|l|}{ Q2 } & \multicolumn{2}{|l|}{ Q3 } & \multicolumn{2}{|l|}{ Q4 } & \multirow[b]{2}{*}{ Obs } & \multirow[b]{2}{*}{ SMR $(95 \% \mathrm{Cl})$} \\
\hline & Obs & SMR $(95 \% \mathrm{Cl})$ & Obs & SMR $(95 \% \mathrm{Cl})$ & Obs & SMR $(95 \% \mathrm{Cl})$ & Obs & SMR $(95 \% \mathrm{Cl})$ & & \\
\hline All causes & 317 & 0.82 (0.74 to 0.99$)$ & 261 & $0.79(0.70$ to 0.90$)$ & 334 & $0.93(0.83$ to 1.03$)$ & 213 & $0.86(0.75$ to 0.98$)$ & 1829 & $0.98(0.94$ to 1.03$)$ \\
\hline All cancers & 79 & 0.70 (0.55 to 0.87$)$ & 81 & 0.89 (0.71 to 1.11$)$ & 103 & $1.01(0.82$ to 1.22$)$ & 69 & $0.92(0.71$ to 1.16$)$ & 514 & $1.04(0.95$ to 1.13$)$ \\
\hline Liver cancer & 4 & 1.40 (0.38 to 3.58$)$ & 2 & 0.86 (0.10 to 3.09 ) & 2 & 0.75 (0.09 to 2.72$)$ & 0 & 0.00 (0.00 to 1.79$)$ & 7 & $0.55(0.22$ to 1.14$)$ \\
\hline Pancreatic cancer & 2 & $0.32(0.04$ to 1.17$)$ & 5 & 1.00 (0.32 to 2.33$)$ & 5 & 0.87 (0.28 to 2.04$)$ & 6 & 1.41 (0.52 to 3.06$)$ & 30 & 1.09 (0.74 to 1.56$)$ \\
\hline Prostate cancer & 5 & 0.66 (0.21 to 1.54$)$ & 8 & 1.15 (0.50 to 2.27 ) & 3 & 0.37 (0.08 to 1.07$)$ & 8 & 1.29 (0.56 to 2.54$)$ & 48 & 1.03 (0.76 to 1.37$)$ \\
\hline Kidney cancer & 1 & 0.32 (0.01 to 1.77 ) & 2 & 0.74 (0.09 to 2.69 ) & 2 & 0.66 (0.08 to 2.38$)$ & 1 & 0.42 (0.01 to 2.34 ) & 18 & $1.23(0.73$ to 1.95$)$ \\
\hline Breast cancer & 5 & 0.80 (0.26 to 1.86$)$ & 3 & 0.88 (0.18 to 2.56$)$ & 2 & 0.73 (0.09 to 2.62 ) & 1 & 1.02 (0.03 to 5.69$)$ & 15 & 1.39 (0.78 to 2.29$)$ \\
\hline Bladder cancer & 1 & 0.40 (0.01 to 2.25 ) & 2 & 0.93 (0.11 to 3.38 ) & 4 & $1.61(0.44$ to 4.13$)$ & 1 & 0.53 (0.01 to 2.97 ) & 8 & 0.62 (0.27 to 1.22$)$ \\
\hline Diabetes mellitus & 4 & $0.39(0.11$ to 1.00$)$ & 4 & 0.47 (0.13 to 1.20$)$ & 11 & 1.17 (0.58 to 2.09$)$ & 8 & 1.14 (0.49 to 2.24$)$ & 64 & 1.42 (1.09 to 1.81$)$ \\
\hline Ischaemic heart disease & 73 & 0.88 (0.69 to 1.11$)$ & 60 & 0.81 (0.62 to 1.04 ) & 68 & 0.82 (0.64 to 1.04$)$ & 47 & 0.88 (0.64 to 1.17$)$ & 444 & 0.95 (0.87 to 1.05$)$ \\
\hline Cerebrovascular disease & 13 & 0.62 (0.33 to 1.05 ) & 13 & 0.73 (0.39 to 1.24 ) & 19 & 0.97 (0.58 to 1.52$)$ & 12 & 1.02 (0.53 to 1.78 ) & 112 & 1.02 (0.84 to 1.23$)$ \\
\hline Chronic renal disease & 6 & 1.61 (0.59 to 3.50$)$ & 2 & 0.63 (0.08 to 2.27$)$ & 3 & 0.87 (0.18 to 2.54$)$ & 3 & 1.24 (0.26 to 3.63$)$ & 13 & $0.72(0.38$ to 1.23$)$ \\
\hline
\end{tabular}


Table 4 HRs for selected causes of death comparing APFO exposure quartiles to the referent population

\begin{tabular}{|c|c|c|c|}
\hline Cancer & Exposure* & HR & $95 \% \mathrm{Cl}$ \\
\hline \multirow[t]{5}{*}{ Prostate } & Referent & 1 & \\
\hline & Q1 & 0.34 & 0.25 to 1.60 \\
\hline & Q2 & 1.12 & 0.53 to 2.37 \\
\hline & Q3 & 0.36 & 0.11 to 1.17 \\
\hline & Q4 & 1.32 & 0.61 to 2.84 \\
\hline \multirow[t]{3}{*}{ Kidney } & Referent & 1 & \\
\hline & Q1-Q2 & 0.38 & 0.11 to 1.23 \\
\hline & Q3-Q4 & 0.39 & 0.11 to 1.32 \\
\hline \multirow[t]{5}{*}{ Pancreatic cancer } & Referent & 1 & \\
\hline & Q1 & 0.32 & 0.08 to 1.35 \\
\hline & Q2 & 0.89 & 0.34 to 2.31 \\
\hline & Q3 & 0.82 & 0.32 to 2.12 \\
\hline & Q4 & 1.23 & 0.50 to 3.00 \\
\hline \multirow[t]{3}{*}{ Bladder cancer } & Referent & 1 & \\
\hline & Q1-Q2 & 1.03 & 0.27 to 3.96 \\
\hline & Q3-Q4 & 1.96 & 0.63 to 6.15 \\
\hline \multirow[t]{3}{*}{ Liver cancer } & Referent & 1 & \\
\hline & Q1-Q2 & 2.09 & 0.69 to 6.31 \\
\hline & Q3-Q4 & 0.67 & 0.14 to 3.27 \\
\hline \multirow[t]{3}{*}{ Breast cancer } & Referent & 1 & \\
\hline & Q1-Q2 & 0.61 & 0.25 to 1.48 \\
\hline & Q3-Q4 & 0.54 & 0.15 to 1.94 \\
\hline \multirow[t]{5}{*}{ Chronic renal disease } & Referent & 1 & \\
\hline & Q1 & 2.24 & 0.82 to 6.12 \\
\hline & Q2 & 0.94 & 0.21 to 4.23 \\
\hline & Q3 & 1.15 & 0.32 to 4.09 \\
\hline & Q4 & 1.37 & 0.38 to 4.95 \\
\hline \multirow[t]{5}{*}{ Ischaemic heart disease } & Referent & 1 & \\
\hline & Q1 & 0.93 & 0.73 to 1.18 \\
\hline & Q2 & 0.87 & 0.66 to 1.13 \\
\hline & Q3 & 0.88 & 0.68 to 1.13 \\
\hline & Q4 & 0.89 & 0.66 to 1.21 \\
\hline \multirow[t]{5}{*}{ Cerebrovascular disease } & Referent & 1 & \\
\hline & Q1 & 0.57 & 0.32 to 1.02 \\
\hline & Q2 & 0.70 & 0.39 to 1.24 \\
\hline & Q3 & 0.93 & 0.57 to 1.53 \\
\hline & Q4 & 0.98 & 0.53 to 1.81 \\
\hline \multirow[t]{5}{*}{ Diabetes } & Referent & 1 & \\
\hline & Q1 & 0.27 & 0.10 to 0.76 \\
\hline & Q2 & 0.42 & 0.17 to 1.04 \\
\hline & Q3 & 0.80 & 0.42 to 1.51 \\
\hline & Q4 & 0.72 & 0.34 to 1.52 \\
\hline
\end{tabular}

death from prostate cancer in the highest-exposed category. ${ }^{15} 16$ This association was not observed in other studies of APFO-exposed workers. ${ }^{12} 19$ The small number of deaths and the relatively crude nature of the exposure assessment limited the interpretation of these prior analyses. Moreover, the associations reported by Lundin et $a l^{16}$ were observed in the internal analysis only, and potentially a function of the very low rate of prostate cancer death in the lowest-exposure group, a mix of production, research and development, and administration workers who may differ from production workers. We addressed this limitation in this updated study by including the Saint Paul plant workers who were similar to the Cottage Grove manufacturing workers, but not exposed to APFO on the job. We also included incident cases of prostate cancer, thus identifying six times as many cases. While the SMRs remained inconsistent across PFOA quartile levels, the HRs for prostate cancer incidence did not suggest a trend. Prostate cancer mortality and incidence have not been associated with PFOA exposure in other populations. ${ }^{12}{ }^{19-21}$ A recent case-control study in a population without occupational exposure reported an
Table 5 HRs for selected cancers comparing APFO exposure quartiles to the referent population

\begin{tabular}{|c|c|c|c|c|}
\hline Cancer & Exposure* & $\mathbf{n}$ & HRt & $95 \% \mathrm{Cl}$ \\
\hline \multirow[t]{5}{*}{ Prostate } & Referent‡ & 253 & 1 & \\
\hline & Q1 & 42 & 0.80 & 0.57 to 1.11 \\
\hline & Q2 & 42 & 0.85 & 0.61 to 1.19 \\
\hline & Q3 & 49 & 0.89 & 0.66 to 1.21 \\
\hline & Q4 & 55 & 1.11 & 0.82 to 1.49 \\
\hline \multirow[t]{8}{*}{ Kidney } & Referent & 19 & 1 & \\
\hline & Q1 & 4 & 1.07 & 0.36 to 3.16 \\
\hline & Q2 & 4 & 1.07 & 0.36 to 3.17 \\
\hline & Q3 & 4 & 0.98 & 0.33 to 2.92 \\
\hline & Q4 & 4 & 0.73 & 0.21 to 2.48 \\
\hline & Referent & 19 & 1.0 & \\
\hline & Q1-Q2 & 8 & 1.07 & 0.46 to 2.46 \\
\hline & Q3-Q4 & 8 & 0.85 & 0.36 to 2.06 \\
\hline \multirow[t]{3}{*}{ Pancreatic cancer } & Referent & 15 & 1 & \\
\hline & Q1-Q2 & 1 & 0.13 & 0.02 to 1.03 \\
\hline & Q3-Q4 & 9 & 1.36 & 0.59 to 3.11 \\
\hline \multirow[t]{5}{*}{ Bladder cancer } & Referent & 43 & 1 & \\
\hline & Q1 & 7 & 0.81 & 0.36 to 1.81 \\
\hline & Q2 & 6 & 0.78 & 0.33 to 1.85 \\
\hline & Q3 & 15 & 1.50 & 0.80 to 2.81 \\
\hline & Q4 & 12 & 1.66 & 0.86 to 3.18 \\
\hline \multirow[t]{8}{*}{ Breast cancer } & Referent & 28 & 1 & \\
\hline & Q1 & 8 & 0.36 & 0.16 to 0.79 \\
\hline & Q2 & 8 & 0.65 & 0.29 to 1.42 \\
\hline & Q3 & 14 & 1.47 & 0.77 to 2.80 \\
\hline & Q4 & 4 & 0.85 & 0.29 to 2.46 \\
\hline & Referent & 28 & 1 & \\
\hline & Q1-Q2 & 16 & 0.46 & 0.25 to 0.87 \\
\hline & Q3-Q4 & 18 & 1.27 & 0.70 to 2.31 \\
\hline
\end{tabular}

association with PFOA among prostate cancer cases who had a first-degree relative with the same diagnosis. ${ }^{22}$

In contrast with our study, PFOA was associated with kidney cancer mortality among DuPont Parkersburg, WV plant workers. ${ }^{12}$ In that plant, the ammonium salt of PFOA was used as a processing aid in the polymerisation of TFE. TFE is a kidney carcinogen in rats, ${ }^{13}$ whereas PFOA is not. ${ }^{2}$ Although PFOA and TFE exposures were highly correlated, Steenland and Woskie $^{12}$ considered only PFOA in their analysis indicating that they assumed that TFE's volatile and explosive properties meant it would be well controlled under normal operations, and thus render appreciable exposure to it unlikely. By contrast, another evaluation of TFE synthesis and polymerisation workers (including $40 \%$ from the DuPont plant), ${ }^{14}{ }^{23}$ reported potential TFE exposure occurring through leaks, opening autoclaves in the polymerisation area, or from decomposition of the polymer. A job-exposure matrix with annual semiquantitative estimates for TFE and PFOA were considered sufficient to identify relative differences in exposure to both compounds. Consonni et al ${ }^{14}$ reported an SMR of 1.4 (95\% CI 0.7 to 2.7) for kidney cancer in the cohort, but could not separate the effects of TFE and PFOA with kidney cancer in their exposure trend analyses. It is possible the results of Steenland and Woskie ${ }^{12}$ are similarly confounded by TFE.

With concern for the PFOA-TFE exposure overlap, we conducted an extensive review of all potential exposure to TFE at the Cottage Grove site for production operations, which indicated that exposures were low and infrequent. The highest volume and most frequent use of TFE occurred in 1982 in a 
pilot plant with, at most, 12 employees potentially exposed for only short-duration tasks across shifts. Infrequent and low volume use occurred in two time periods, 1979-1981 and 1983-1990, when fewer than four workers could have had minimal exposure to TFE due to the frequency of operations and control systems. No TFE was used in any operations on the Cottage Grove site prior to 1978 or after 1991. Monitoring data and potential exposure tasks indicated that full-shift TWA TFE exposures were below $0.02 \mathrm{ppm}$ for the highest-volume production year (1982) and $0.002 \mathrm{ppm}$ other years with low production. These levels are more than 100 times below the occupational exposure limit. These factors indicate our study presented an opportunity to address APFO exposure in near isolation. The absence of an APFO-kidney cancer association suggests prior associations of PFOA/APFO with kidney cancer may be due to confounding from TFE exposure.

Our results are consistent with the lack of epidemiologic evidence in humans for liver cancer associated with PFOA, as the populations previously studied were highly exposed occupational workers, ${ }^{12}$ a lesser-exposed community through drinking water, ${ }^{19}{ }^{21}$ and the general population. ${ }^{20}$ We observed a modest HR for pancreatic cancer for the combined two highest quartiles of PFOA exposure in our study. A non-significant trend for pancreatic cancer and plasma PFOA levels was reported in a Danish case-cohort study of the general population. ${ }^{20}$ Pancreatic cancer was not reported to be associated with PFOA in other studies where the population was exposed at much higher levels $^{12}$ or through drinking water that contained PFOA. ${ }^{19} 21$

Because of its low case-fatality rate, testicular cancer is not well characterised by mortality data. ${ }^{12}$ We observed too few incident testicular cancers to perform an exposure-response analysis. As part of the C8 Health Project, Barry et $a l^{19}$ reported a trend for testicular cancer in a community cohort exposed to PFOA. From the same project, an analysis using other cancers as the referent population, Vieira ${ }^{21}$ also reported an increased risk for testicular cancer in a water district that had PFOA in the water; five neighbouring water districts with lesser amounts of PFOA in the water did not have increased risks for testicular cancer.

Butenhoff et $a l^{5}$ reported a suspected increased incidence of mammary gland adenomas in rats, but the distribution was within published background variation. A subsequent pathology working group re-examined the histology and confirmed no statistically significant differences between treatment groups. ${ }^{24} \mathrm{~A}$ small case-control study $(n=31$ cases) reported a modest association between diagnosed breast cancer and serum PFOA, but the postdiagnostic PFOA measurement made the results difficult to interpret. ${ }^{25}$ We did not observe an increased incidence of breast cancer in this occupational cohort, nor was it observed in a combined community/occupational cohort study. ${ }^{19}$

An epidemiologic controversy exists whether PFOA is associated with higher cholesterol levels in humans in contrast with the hypolipidemic effect as a PPAR $\alpha$ agonist in rodents. ${ }^{26}$ The magnitude of the cholesterol effect in humans has been inconsistently reported across PFOA exposure levels of these predominantly cross-sectional studies. ${ }^{27}$ Fletcher et $a l^{28}$ recently suggested PFOA may promote a hypercholesterolemic environment with potential implications for human disease as they studied 290 individuals of an exposed community who had an inverse association between PFOA and whole-blood expression of a subset of genes involved with cholesterol mobilisation. Our finding of a lack of an association for cardiovascular disease or stroke mortality in this highly exposed PFOA cohort concurs with similar results from another occupational cohort. ${ }^{12}$
Increased trends for the incidence of heart disease and stroke were not consistently reported among a series of analyses undertaken to assess risk in a community whose drinking water contained PFOA. ${ }^{29-31}$

Some limitations should be considered when interpreting the results of this analysis. The new EDM incorporated substantial task-based detail, but there was potential for exposure misclassification, particularly from episodic peak exposures. While EDMs are not well suited for capturing such events, it is likely the workers were already classified in the high-exposure category. We also did not have information on lifestyle factors or other jobs: a common problem in occupational cohorts. A non-APFO production site was included as a referent population to partially address these concerns, as they should have similar frequencies of these lifestyle and other occupational exposure factors. Linking the cohort to the Minnesota and Wisconsin cancer registries provided an excellent opportunity to more fully explore cancer risks potentially associated with APFO exposure. Nevertheless, the follow-up for cancer incidence was limited to 1988 onward. It is likely we missed incident, but nonfatal cancers occurring before 1988. This is particularly a consideration for thyroid and testicular cancer for which incidence peaks at earlier ages. Finally, the cancer registries did not cover cohort members who left Minnesota and Wisconsin and, based on the proportion of deaths outside these states, there was an under-ascertainment of cancer cases in the two lower-exposed quartiles of the Cottage Grove workers.

Notable strengths of this study are the completeness of follow-up, the improved exposure reconstruction, and the near absence of TFE exposure. The ability to link this cohort to two cancer registries allowed for a better examination of the burden of cancers that are not highly fatal. The inclusion of a large non-APFO-exposed referent population was also a strength. The exposure estimates for the APFO production areas were based on objective monitoring data, but the estimates for non-APFO production areas in the Chemical Division, the Non-Chemical Division, and the Saint Paul Plant workers were based on expert judgment. Though limited, some available biomonitoring data provide a measure of external validity for the exposure categorisations developed from PFOA air monitoring and professional judgment used in the present study. A PFOA biomonitoring programme was offered to Chemical Division employees in conjunction with medical surveillance activities in 1993, 1995, 1997 and 2000. ${ }^{632} 33$ PFOA concentrations for the 148 participants in 2000 were $\log$ normally distributed with a geometric mean serum PFOA concentration of $815 \mathrm{ng} / \mathrm{mL}$ (95\% CI 608 to $1094 \mathrm{ng} / \mathrm{mL}$ ). This was similar to previous cross-sectional biomonitoring surveys of this occupational population. ${ }^{32}$ The 50 participants who worked only in the PFOA-related manufacturing areas had a geometric mean serum PFOA concentration of $2538 \mathrm{ng} / \mathrm{mL}$ (95\% CI 1626 to $3961 \mathrm{ng} / \mathrm{mL}$ ). The 38 Chemical Division employees whose job involved some work in PFOA manufacturing areas had a geometric mean PFOA of $979 \mathrm{ng} / \mathrm{mL}$ (95\% CI 565 to $1695 \mathrm{ng} / \mathrm{mL}$ ). The 60 Chemical Division employees who had never worked in these PFOA manufacturing areas had a geometric mean PFOA of $282 \mathrm{ng} / \mathrm{mL}$ (95\% CI 194 to $410 \mathrm{ng} / \mathrm{mL})$. By contrast, 100 American Red Cross blood donors from the Minneapolis-Saint Paul area in 2000-2001 had a geometric mean serum PFOA concentration of $4.5 \mathrm{ng} / \mathrm{mL}$ (95\% CI 4.1 to $4.7 \mathrm{ng} / \mathrm{mL}$ ), ${ }^{34}$ which was similar to results from the nationally representative sample determined from the National Health and Nutrition Examination Survey in 1999$2000 .^{35}$ A study assumption was that the Non-Chemical Division workers likely had serum PFOA levels lower than the 
Chemical Division workers who never worked in the PFOA manufacturing area but higher than those reported in the general population. The biomonitoring data support our assertion that indirect occupational exposure existed at the site.

In summary, we did not observe an association between occupational APFO exposure and the risk of dying or developing liver, pancreatic, testicular, kidney, prostate, breast, bladder, and thyroid, cancers, though the power to evaluate some cancers was limited. We also did not see evidence of elevated risks of mortality from ischaemic heart disease, cerebrovascular disease, or chronic renal disease.

Acknowledgements The authors wish to thank the Minnesota Cancer Surveillance System and the Wisconsin Cancer Reporting System for assistance with this study. We particularly wish to thank Sally Bushhouse of MCSS and Laura Stephenson of the WCRS for their assistance.

Contributors All authors contributed significantly to the study design, data acquisition, or analysis. All authors contributed to the preparation of the manuscript and reviewed the final draft.

Funding This work was supported by a grant to the University of Minnesota from the 3M Company. The investigators at the University of Minnesota had final responsibility and authority for the study design, analysis results, conclusions and preparation of the manuscript. University of Minnesota investigators had full access to all records required for the study. KR was supported, in part by the Occupational and Environmental Epidemiology Training Program of the Midwest Center for Occupational Health \& Safety CDC/NIOSH T42OH008434.

Ethics approval University of Minnesota Human Subjects Committee.

Provenance and peer review Not commissioned; externally peer reviewed.

Open Access This is an Open Access article distributed in accordance with the Creative Commons Attribution Non Commercial (CC BY-NC 3.0) license, which permits others to distribute, remix, adapt, build upon this work non-commercially, and license their derivative works on different terms, provided the original work is properly cited and the use is non-commercial. See: http://creativecommons.org/ licenses/by-nc/3.0/

\section{REFERENCES}

1 Biegel LB, Hurtt ME, Frame SR, et al. Mechanisms of extrahepatic tumor induction by peroxisome proliferators in male CD rats. Toxicol Sci 2001;60:40-55.

2 Butenhoff JL, Kennedy GL Jr, Chang S-C, et al. Chronic dietary toxicity and carcinogenicity study with ammonium perfluorooctanoate in Sprague-Dawley rats. Toxicology 2012;298:1-13.

3 Frame SR, McConnell EE. Review of proliferative lesions of the excocrine pancreas in two chronic feeding studies in rats with ammonium perfluorooctanoate. Du Pont Laboratory Project Identification \# 13788. 2003;AR226-1920. USEARN.

4 Elcombe CR, Elcombe BM, Foster JR, et al. Hepatocellular hypertrophy and cell proliferation in Sprague-Dawley rats following dietary exposure to ammonium perfluorooctanoate occurs through increased activation of the xenosensor nuclear receptors PPARalpha and CAR/PXR. Arch Toxicol 2010;84:787-98.

5 Butenhoff J, Costa G, Elcombe C, et al. Toxicity of ammonium perfluorooctanoate in male cynomolgus monkeys after oral dosing for 6 months. Toxicol Sci 2002;69:244-57

6 Olsen GW, Zobel LR. Assessment of lipid, hepatic, and thyroid parameters with serum perfluorooctanoate (PFOA) concentrations in fluorochemical production workers. Int Arch Occup Environ Health 2007:81:231-46.

7 Woskie SR, Gore R, Steenland K. Retrospective exposure assessment of perfluorooctanoic acid serum concentrations at a fluoropolymer manufacturing plant. Ann Occup Hyg 2012;56:1025-37.

8 Olsen GW, Mair DC, Church TR, et al. Decline in perfluorooctanesulfonate and other polyfluoroalkyl chemicals in American Red Cross adult blood donors, 20002006. Environ Sci Technol 2008;42:4989-95.

9 Kato K, Wong LY, Jia LT, et al. Trends in exposure to polyfluoroalkyl chemicals in the U.S. Population: 1999-2008. Environ Sci Technol 2011:45:8037-45.
10 D'Eon JC, Mabury SA. Is indirect exposure a significant contributor to the burden of perfluorinated acids observed in humans? Environ Sci Technol 2011:45:7974-84.

11 Frisbee SJ, Brooks AP Jr, Maher A, et al. The C8 health project: design, methods, and participants. Environ Health Perspect 2009;117:1873-82.

12 Steenland K, Woskie S. Cohort mortality study of workers exposed to perfluorooctanoic acid. Am J Epidemiol 2012;176:909-17.

13 National Toxicology Program. NTP toxicology and carcinogenesis studies of terafluoroethylene (CasNo. 116-14-3) in F344/N rats and B6C3F1 mice (inhalation studies). NIH Publication No. 97-3366. Research Triangle Park, NC: National Institute of Environmental Health Sciences, 1997.

14 Consonni D, Straif K, Symons JM, et al. Cancer risk among tetrafluoroethylene synthesis and polymerization workers. Am J Epidemiol 2013;178:350-8.

15 Gilliland FD, Mandel JS. Mortality among employees of a perfluorooctanoic acid production plant. J Occup Med 1993;35:950-4.

16 Lundin Jl, Alexander BH, Olsen GW, et al. Ammonium perfluorooctanoate production and occupational mortality. Epidemiology 2009;20:921-8.

17 Schubauer-Berigan MK, Hein MJ, Raudabaugh WM, et al. Update of the NIOSH life table analysis system: a person-years analysis program for the windows computing environment. Am J Ind Med 2011;54:915-24.

18 Breslow NE, Day NE. Statistical methods in cancer research. Lyon: International Agency for Research on Cancer, 1987.

19 Barry V, Winquist A, Steenland K. Perfluorooctanoic acid (PFOA) exposures and incident cancers among adults living near a chemical plant. Environ Health Perspect 2013;121:1313-18.

20 Eriksen KT, Sorensen M, McLaughlin JK, et al. Perfluorooctanoate and perfluorooctanesulfonate plasma levels and risk of cancer in the general Danish population. J Natl Cancer Inst 2009;101:605-9.

21 Vieira VM, Hoffman K, Shin HM, et al. Perfluorooctanoic acid exposure and cancer outcomes in a contaminated community: a geographic analysis. Environ Health Perspect 2013;121:318-23.

22 Hardell E, Karrman A, van Bavel B, et al. Case-control study on perfluorinated alkyl acids (PFAAs) and the risk of prostate cancer. Environ Int 2014;63:35-9.

23 Sleeuwenhoek A, Cherrie JW. Exposure assessment of tetrafluoroethylene and ammonium perfluorooctanoate 1951-2002. J Environ Monit 2012;14:775-81.

24 Hardisty JF. Pathology peer review and pathology working group review of mammary glands from a chronic feeding study in rats of PFOA. U.S. EPA Docket AR-226. Research Triangle Park: Experimental Pathology Laboratories, Inc., 2005.

25 Bonefeld-Jorgensen EC, Long M, Bossi R, et al. Perfluorinated compounds are related to breast cancer risk in Greenlandic Inuit: a case control study. Environ Health 2011;10:88.

26 Vanden Heuvel JP. Comment on "associations between PFOA, PFOS and changes in the expression of genes involved in cholesterol metabolism in humans" by Fletcher et al., Environment International 57-58 (2013) 2-10. Environ Int 2013:61:150-3.

27 Steenland K, Fletcher T, Savitz DA. Epidemiologic evidence on the health effects of perfluorooctanoic acid (PFOA). Environ Health Perspect 2010;118:1100-8.

28 Fletcher T, Galloway TS, Melzer D, et al. Associations between PFOA, PFOS and changes in the expression of genes involved in cholesterol metabolism in humans. Environ Int 2013;57-58:2-10.

29 C8 Science Panel. Probable Link Evaluation of Stroke. 2012. http://www. c8sciencepanel.org/pdfs/Probable_Link_C8_Stroke_30Jul2012.pdf

30 Simpson C, Winquist A, Lally C, et al. Relation between perfluorooctanoic acid exposure and strokes in a large cohort living near a chemical plant. Environ Res 2013;127:22-8

31 C8 Science Panel. Probable Link Evaluation of Heart Disease. 2012. http://www c8sciencepanel.org/pdfs/Probable_Link_C8_Heart_Disease_200ct2012.pdf

32 Olsen GW, Burris JM, Burlew MM, et al. Plasma cholecystokinin and hepatic enzymes, cholesterol and lipoproteins in ammonium perfluorooctanoate production workers. Drug Chem Toxicol 2000;23:603-20.

33 Olsen GW, Butenhoff JL, Mandel JH. Assessment of lipid, hepatic, and thyroid function in relation to an occupational biologic limit value for perfluorooctanoate. USEPA Public Docket AR-226-1351. Saint Paul: 3M Company, 2003.

34 Olsen GW, Church TR, Miller JP, et al. Perfluorooctanesulfonate and other fluorochemicals in the serum of American Red Cross adult blood donors. Environ Health Perspect 2003;111:1892-901.

35 Calafat AM, Kuklenyik Z, Reidy JA, et al. Serum concentrations of 11 polyfluoroalkyl compounds in the U.S. population: data from the National Health and Nutrition Examination Survey (NHANES). Environ Sci Technol 2007:41:2237-42. 